Radau's tables). It is of interest to note that the latter corrections are much the smaller.

The observed errors of the wireless time signals received from Paris, Nauen, and Annapolis are shown in Table IV. (p. A I6). The range of error, from about $0.2 \mathrm{sec}$. early to $0.4 \mathrm{sec}$. late for each of the three observatories, is rather large when the installations for determining and keeping time at the observatories concerned are considered. The observations, however, have not been corrected for errors in the sending. It is not stated to which series of morning signals the 'Paris observations refer, and it would be of value to any one discussing these results to know whether the beginning, middle, or end of the signal was referred to the local clock beat.

The next section deals with the measures of the photographs of the sun taken at Greenwich, the Cape, Kodaikanal, and Dehra Dun. Thanks to this cooperation, photographs were available for each day of the year. There is a pronounced decline in the mean daily area of spots, corrected for foreshortening,

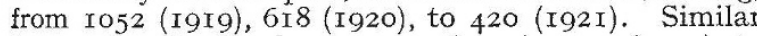
figures for the faculæ are I729 (I9r9), I219 (I920), to 739 (I92I), the unit being the millionth of the sun's visible hemisphere. The last section gives the usual details concerning the magnetical and meteorological observations. These form about one-third of the whole volume. Plates show the magnetic disturbances for three consecutive days, May I3, I4, and $\mathrm{I} 5$.

In one respect the title, " Greenwich Observations, I92I," does the book less than justice. Except in the annual report at the end of the volume, there is, for example, no mention of the work done with the Thompson Equatorial, with which more than Iooo parallax plates were taken, and almost as many measured. There is no question that the national observatory at Greenwich continues to maintain its high standard of duty and performance, though one may require to read between the lines to prove it.

The Cape portion of the Astrographic Chart and Catalogue extends from declination $-40^{\circ}$ to $-52^{\circ}$. The volume of the catalogue now issued ${ }^{2}$ is the eighth of this series to appear. The previous members, numbers i.-vii., give the measures in the seven zones from $-4 \mathrm{I}^{\circ}$ to $-47^{\circ}$, the first appearing in $\mathrm{I} 9 \mathrm{I} 3$, and the last in 1923 .

The present volume was delayed in printing, apparently by the War, for the introduction was signed by the late Mr. S. S. Hough in I9r6. It contains the measures of the rectangular co-ordinates of all the stars shown on the plates having their centre on the declination circle $-50^{\circ}$.

The introduction gives a short description of the telescope, the method of measurement of the plates, the process followed to guard against errors in the measuring, and the further checking of the results by the intercomparison of overlapping plates. It is evident that great care has been taken to eliminate errors.

The plates were exposed during the years I902r9o8 and measured with two exceptions between November 1907 and September 1908. The catalogue gives the measures of the $x$ and $y$ co-ordinates to O.OOI, an estimation of the diameter of the image, together with the identification by number and magnitude of the star in the Cape Photographic Durchmusterung, if it occurs in that catalogue. No attempt is here made to convert these estimates of stellar diameter into a standard scale of magnitude.

The catalogue proper consists of 465 pages, with a total of 79, IO5 stars, or a distribution for the first 12 hours of R.A. of 32,504 and for the last I 2 hours of 46,601 .

2 Catalogue of Rectangular Co-ordinates and Diameters of Star Images derived from Photographs taken at the Royal Observatory, Cape of Good Hope. Zone $-50^{\circ}$.

\title{
Annual Meeting of the Geographical Association.
}

THE annual meeting of the Geographical Association was held at the London School of Economics on the first three days of January. The gathering was remarkable for an extraordinarily valuable series of papers of high scientific worth, for a broadcast message by Prof. J. L. Myers, the president, and for a continuation of the plan of inviting a distinguished continental thinker, in this case Dr. A. Sommerfelt, of Oslo, to speak.

In his presidential address, Prof. Myers dealt with the historical method in ethnology and with cogent argument and gentle banter criticised the conclusions of some investigators, especially Mr. Perry, who, applying the hypothesis of long distance diffusion of culture, announced as discoveries speculations which recalled extreme conclusions of Max Müller on the Aryan Race or those of the Anglo-Israelites on the lost tribes.

Among the other papers two stood out as remarkable. One was entitled on the programme "Life among the Hill Tribes of Algeria." It cannot be described satisfactorily either as a description illustrated by films or as films with appropriate comments, for the first of the noteworthy points just was that it was a coherent whole in the sense that the words and music of a good song are coherent. The kinema was in fact seen at its best as an educational instrument of the highest class. It is not easy to make it so, but that it can be done is evident. The second point is that what was done was worth doing. The films were thoroughly scientific, extremely human, entirely free from anything meretricious and yet extraordinarily interesting. They are the property of
Mr. J. A. Haeseler, who is collecting a scientific library of such films, and they had been taken with the help of Capt. Hilton-Simpson, who gave the address. They showed the actual life of the people: basket-making, shoemaking (with platted grass), making of wooden door-locks with an adze strikingly like a bronze age tool, quern-making and corn grinding, ploughing, skinning a goat and the processes by which the skin is turned into a water-bottle, and bread-making; but perhaps the most fascinating of the pictures were those showing the fundamental arts of textile and pottery making. Spinning was exhibited as carried on by two or three of the simplest possible methods, one even without the aid of a spindle, while two types of simple looms, and the entire operation of weaving from the making of the warp and setting up of the loom to the final process of inserting the woof, was shown with wonderful clearness. So also clay was obtained from a pit, freed from stones, and a pot gradually built up before one's eyes without-and this is the remarkable fact- the aid of the potter's wheel. The ornamenting of the pot, the firing, the fire being lit by a boy, and the glazing of the still hot vessels were equally clearly shown.

The performance-it is difficult to find a satisfactory word for the combined appeal to eye and ear--gave an insight not only into the geography of another land, but also into conditions of a long past time very thinly veiled by later growths and accretions. We have said that the kinema was seen at its best. This was because it was used for what it is best fitted. It was used to show things as they happened, 
dynamically, not statically. We might perhaps qualify our statement and say " almost at its best." It would have been better, though impracticable, to show several of the films again. Even when one knew what to look for, it was quite impossible to follow all the details of what was done. Further, it was obvious that while for exhibiting processes the film is the superior, yet for still life and for analysis the slide has still the advantage.

The other paper was by Mr. C. E. P. Brooks and was entitled "The Climatic History of the Fiord Countries." Climatology is still in its infancy, and this is one of the few papers which deal with climatic, as distinct from meteorological, problems without becoming unintelligible amid a maze of statistics. Mr. Brooks traced out the succession of climates during and since the Ice Age, if indeed we are out of the Ice Age. He suggested that the Daun stadium should be dated round about I 800 B.C. rather than 5000 B.C., and estimated the temperature of the Norwegian coast at 5000 B.c. to have been $4^{\circ}$ higher than at present. His most striking suggestion related to the causes of these climatic changes. He associated them with variations in the ice conditions in the Arctic Ocean. Analysis of these conditions by Kerner Marilaun and himself has shown that the Arctic floating ice-cap must either have its present extent or the whole ocean must be free of ice, no intermediate stage being stable. He related the voyages of the Norsemen, who in their voyages to the south of Greenland mention storms but never ice, and the great Asiatic migrations, to an open period in which the Arctic was unglaciated, and concluded, "In the twelfth century the glacial stage recurred and has apparently persisted to the present day." So we are still in the Ice Age !

\section{Periodicals in Canadian Libraries. ${ }^{1}$}

THE need for co-operative library catalogues of scientific periodicals has long been felt in many countries, and various projects have been undertaken to supply the deficiency. The work before us is an attempt to provide for those specially interested in scientific periodicals, and consists of a list of such material available in Canadian libraries, together with bibliographical information. Journals are arranged under their latest form of title, and publications of academies under the name of the society or institution. In our opinion, this method of listing the publications of academies does not facilitate their ready identification. Under the words "Kaiserlich" and " Königlich " there are quite a number of entries, although events of recent years have caused these adjectives to be dropped or replaced. As an example, the Königlich-Preussische Akademie der Wissenschaften is now known as the Preussische Akademie, though this fact cannot be ascertained from the present work. Had publications of this character been listed under the first word of their title--in this case Sitzungsberichte-consultation would have been simplified.

It is to be regretted that a number of Canadian libraries, whilst those responsible realised the importance of the work, were unable to include their possessions in this list. The reasons given were that periodicals were not catalogued or that the staff at their disposal was inadequate. It is obvious that full advantage cannot be taken of the resources of Canadian libraries if a proportion of them are com-

1 A Catalogue of Scientific Periodicals in Canadian Libraries. Prepared by Dr: Gerhard R. Lomer and Margaret S. Mackay. Pp. xx + 255. (Montreal : McGill University, I924.) n.p. pelled to neglect the preservation and cataloguing of seriails. Further, Canadian science will be under a distinct handicap until steps are taken to provide the libraries with adequate competent assistance.

Despite the difficulties confronting them, the compilers have produced a work which should prove of considerable aid to scientific workers in the Dominion, and they are to be congratulated upon the completion of a volume which bears evidence of much care and painstaking labour. Due credit should also be given to the Canadian Department of Scientific and Industrial Research, the material co-operation of which enabled the early publication of the volume.

F. W. CliffFord.

\section{University and Educational Intelligence.}

AbERDEEn.-The Fullerton Research Scholarship in natural science has been awarded to Miss Elizabeth T. Geddes.

GLASGOW.-The King has been pleased to approve the appointment of Mr. James Montagu Frank Drummond to the regius chair of botany in the University, vacant by the retirement of Prof. F. O. Bower. Mr. Drummond took first-class honours in the Natural Sciences Tripos at Cambridge in I904, and gained the Frank Smart Studentship for research in botany at Gonville and Caius College. He became lecturer in botany at Armstrong College, Newcastleupon-Tyne, and in I909-I92I was lecturer. in plant physiology in the botany department of the University of Glasgow. Since r 921 he has been Director of the Scottish Plant Research at Corstorphine, Edinburgh. During the War he served in Palestine, Egypt, and France, acting as battalion intelligence officer, and afterwards as brigade education officer. His published works refer chiefly to plant physiology, but include a series of papers on the "Botany of the Palestine Campaign " communicated to the Linnean Society.

LoNDON.-The lectures which were to have been given early this month by the late Prof. J. I. Hunter at University College on "The Anatomy and Physiology of the Sympathetic Innervation of the Striated Muscle "will be delivered by Prof. G. Elliot Smith on January I9, 26, and February 2 at 5 o'clock.

The degree of Ph.D. in Science has been conferred on Mr. W. Jevons (Imperial College-Royal College of Science) for a thesis entitled "Spectroscopic Investigations in connexion with the Active Modification of Nitrogen " and other papers.

Notice is given by the Imperial College of Science and Technology, South Kensington, of the alteration in the date of the Entrance Scholarship Examination, which in I925 will begin on April 24. Eighteen Scholarships, value $62 l$. Ios. each, are offered, six being tenable at the Royal College of Science, six at the Royal School of Mines, and six at the City and Guilds (Engineering) College, for admission at the beginning of the session, namely, the first Tuesday in October. Prospectuses and full particulars may be obtained on application to the Registrar, Imperial College, South Kensington, S.W.7.

Applications are invited by Yale University for two Theresa Seessel Research Fellowships for the promotion of original research in biological studies, each yielding $300 l$. Preference will be given to candidates who have already obtained their doctorate, and have demonstrated by their work fitness to carry on 